\title{
The word processor and the shift in visual design of the short story
}

\author{
...form is not something that the poet gives to things \\ it is something he receives from things... \\ every experience has its own inherent and unrepeatable form \\ which lies there to be discovered... \\ - Denise Levertov, NYR Nov 4, 2004
}

I have become particularly interested in the layout innovations which are occurring within the short story form in the ordering of the story, the further development of the notion of narrative assembly. Some writers have found or re-found new ways of working with reader focus, of creating narrative tension, of managing the movement of the story, and of game-playing.

The fiercest outburst during the editing of Best Australian Stories was between the editorial staff of Black Inc and me over the question of the visual layout of the stories selected for publication in the book.

In an essay in Spectrum (Sydney Morning Herald, February 19, 2005) comparing Best Australian Stories 2004 with Best American Stories 2004, I said, 'The Best American has no such layout play apart from the usual white spacing for section breaks and I suspect that the stories had been homogenised into "standard editing practice" styles of the magazines from which they were taken.' I was attacked by one critic, Rob O'Neill, for encouraging what he called 'clever Microsoft formatting' in Best Australian Stories 2004.

However, layout of a story is a way of navigating the reader.

Spacing within a story (for example, section breaks within the story) is known technically as the subordination - the sub-ordering - of the story. Punctuation, along with layout, is a way of narrative guiding and directing. As in film directing, it has to do with optics and perhaps a little with 'breathing', although I find that long-standing theory now a little unconvincing. It is the eye, and then the psychological focus, not the breathing, which is being manipulated. It is part of the navigational method of fiction.

All such ordering and all use of marks within a story are the aesthetic responsibility (conscious or unconscious) of the writer.

I first began to realise a shift in the 'look' of the short story while teaching a graduate workshop at the University of Texas in Austin. Sure, quite a few fine stories were being written in the traditional formats and in the realist genre and will continue to be, I hope, but I could see that for some writers layout was beginning to play a serious part in the aesthetics of the story. 
I had a hunch that it was the word processor which was inviting this, permitting it, suggesting it, and that there was now an advanced layer of communication, new tools, being brought to bear on the short story. (There may be some novelty use of the tools of the wp which, once experimented with, will be discarded as just novelty and of no use in narrative.)

The layout or format of the story has always been evolving and it took huge formalistic leaps during the 1960-1970s revival, with the appearance of subtitling, itemisation, use of visuals, and 'found' story formats (say, in the shape of a box label or the chain letter of messages left on a telephone answering machine - mimicry of found forms). Donald Barthelme is a prime example from this period.

Going further back, the great innovators of the layout of narrative were the writers Laurence Sterne (1713-1768), with Tristram Shandy (which pretty much did it all), and James Joyce (1882-1941), especially in Ulysses in the chapters 'Circe' and 'Ithaca', and John Dos Passos (1896-1970), in USA with his use of 'newsreels'.

More recently, Sebald who owes much to all these writers, is an example of a writer who overuses his particular prose organising techniques to the point of tedium and loss of effect.

One simple typographic and punctuational innovation was the dash. (In the pure sense all layout is punctuational, defined as the system or arrangement of marks used to interrupt or create intervals in a string of words). Sterne in the eighteen century was playing with the dash in narrative, and well into the early twentieth century the dash was still followed by a comma, so the punctation practice was comma/dash as in ,- . I last saw this form used in some stories published in 1916, and Thoreau used it. There are still some purists who feel the dash is lazy punctuation. Sterne also introduced the use of the dash sometimes in place of quotation marks for dialogue, although he also sometimes used both. There are now at least three conventions for laying out dialogue and strangely, each seems to give the work a different rhythm. Maybe this is my imagination. Joyce continued and perhaps finally established Sterne's use of the dash for indicating dialogue although with a much shorter dash.

What this shows to me is that a device or practice is not negated by having been used before. As with many of our signs and indicators in narrative they can sometimes be brought into play time and time again, sometimes according to fashion. Edmund Wilson back in around 1920 pronounced the use of lower case in prose and verse 'old hat'. I found that in the case of one of my Best Australian Stories 2004 contributors, i.j.oog, I liked his use of lower case and thought 'what the hell - if he wants to go lower case, let him go lower case.' It also seems to me that it gives an energy charge to the story. If that someone doesn't know that it has been used many times before in the past, so what? It doesn't mean that the writer using it is therefore disqualified from using it as long as its use comes from an integral sense of appropriateness and effectiveness.

The design of a story, as with punctuation, directs the interaction between the story and reader and can be a representation of the narrative mind. As well, spacing can be used for timing and manipulation of the reading rhythm, which in turn determines pacing and movement of the narrative.

When editing Best Australian Stories 2004 I tried to preserve this design element in publication and struck both resistance from editors who were 
drawn more to 'standard' publishing practices and, oddly, some lack of confidence among writers when it came to discussing their layout of their stories. Finally, the copy editor and the publisher both generously acceded to my request that the stories, as far as layout and spacing (apart from typeface and obvious technical editing - although what that may be is debatable too!) were concerned, be printed as they were sent in.

Earlier before the discussion, the copy editor inserted asterisks (in Texas the students call it a star - asterisk means star in Latin) instead of white space, and I said to the writer that we would change it back. The writer said, 'No, I like what the editor has done'.

When asked about the way they had laid out their stories some writers felt my questions were criticisms and that they were being challenged because they had no rationale for it. I found that they were too quick to surrender back to publishing conventions. I realised that much of the way they laid out their stories was done intuitively or subconsciously which, in my mind, did not make it any less valid. Maybe they feared that they were being tricksy. I had to say, 'that's the way you chose to present the story - it was a set of choices you made intuitively - I want to keep it the way it is'.

One author, Joanna Kujawa, said that the editor of the magazine Heat, Ivor Indyk, had in fact, changed the layout of her story and the paragraphing to the fit the magazine's 'guidelines'. I was dumbfounded.

As with Black Inc, I had to say that the uniformity of 'house style' was for the efficiency of fast production of newspapers or for rigid magazines such as The Readers' Digest and did not suit imaginative prose.

As editors it is our job to recognise and in some cases detect the subtly of the work's visuality and even defend it against the author's intimidated, defenceless or inarticulate collapse in the face of questioning, to see that their willingness to comply with editing - to avoid being seen as 'a prima donna' or a nuisance - was a surrender of their imaginative freedom.

I have toyed with the idea that the stories should be published as facsimiles of the submitted manuscripts (treating the manuscript as the artifact), that is, after technical editing of obviously overlooked errors by the writer, such as repetition of words. But maybe writers see the manuscript as an artifact designed to exist only in that strange temporary space between sending it out to an editor and publication, the pre-publication condition. That is, the designoriented writer is content to produce a manuscript which pleases them without intending that it would be published that way. Certainly, I think that designed, title-pages for manuscripts are usually of this nature. They are a form of hand-crafting not intended for eventual publication.

Is there such a thing as a random mark or a random use of spacing or even randomness in any layout moves? There is unintentional punctuation - or misunderstood punctuation. But can there ever be unmeant layout? Or is it somehow what the writer really wants? Is it related more to personal style than to convention?

Just about all the format devices I am talking about have been around before the word processor and could be done with the typewriter. Alternatively, a writer could request them from a printer or indulgent publisher by inserting instructions in the story to the editor and printer about how it is to look. Verse has always used the arrangement of lines (see the many examples in Best Australian Poems 2004, edited by Les Murray). Indeed, there was a time of extreme experimentation with poetry called 'concrete poetry', which involved 
moving the page around in the typewriter so that the words were arranged, for example, in a snake pattern when writing a poem about a snake or in a rain drop patterns when writing about rain. Concrete verse, however, was not much more than a game to play on a wet afternoon.

But my hunch is that the word processor invites changes to layout by making it easy to do it and easy to change it back - it invites play and experiment.

You can indent easily, or flush right or flush left, look at it, and then change it back if you don't feel it achieves anything.

You can draw with a word processor (stop!).

I detect in this layout play some impulse towards older theories and virtues of the Arts and Crafts Movement, such as the idea that a 'book is to be seen as a unified art object created by one hand'. The author is graphic designer, typesetter, printer, wrapping clerk, and even bookseller in the mode of Jim Cairns, who would take his self-published books and sell them from a table at a conference or at the community market and by so doing link himself faceto-face with the potential reader for conversation.

Arts and Crafts ideas lie behind some self-publishing, but as we know, it is more often vanity or frustration which drives people to self-publish.

What then is the layout palate that writers are using now?

Firstly, the word processor still keeps the story within the same rectangular grid of the modernist book and magazine. Even the word processor cannot write in circles (thank god) except, I suppose, by going to the 'draw' program. Prose belongs to the grid of the rectangular or square page with margins, with the text set usually flush left and with lines reading left to right and then dropping one or more spaces to the next line and continuing over the page. But much innovation and play can be done within the grid. The most playful of the literary magazines is the Melbourne Sleepers Almanac produced by Zoe Dattner and Louise Swinn and it strains against the grid.

A British graphic designer said that to break too far from the grid opens 'too many aesthetic options' which are overwhelmingly beyond the effective management by, or the needs of, most writers (who have other things to deal with). To go too far into graphic design - that is, beyond that point where it is part of the narrative - takes the writer away from their talent, which is for words/ideas/verbal imagery, into the role of graphic designer without (usually) having the talents or training of a visual designer. Look at the madness of authors who think they have 'good ideas' for the cover of their books (that includes me).

I think, too, that the author should stay away from play with type face (font). I can't detect any way that font can be seen as a narrative tool. In manuscript though, writers do play with font. Most use the standard Times New Roman or my favourite Book Antiqua or its Palatino clone, but some decide for reasons I cannot determine to use sans serif fonts. Optical testing has shown that sans serif has an element of reading difficulty when used in body text. Some use other fancy fonts. I know that Dave Eggers' publishing house McSweeneys at first allowed its authors to choose the font for their books and to design the cover, however in his first anthology of short stories he returned to standard practice in the layout and font.

ABC's Radio National broadcaster, Catherine Freyne, said recently, 
Once upon a time, it was just printers and graphic designers who had to worry about typography. But now, in the age of home computers, we all make choices every day about which font to use in presenting written work. Fifteen years ago would you have been able to name five different typefaces? Bet you can now though.

Call me old fashioned, but I have a feeling that the typeface choice is the boundary line between the author-as-verbal artist and the graphic designer. Authors should not choose fonts. They may choose italics or roman, bold or regular, capitals or lower case, yes, but only in exceptional circumstances the page margins, gutters, fonts, and the font size. But I suppose if an author was adamant that he or she wanted to have the story in Copperplate gothic light (or whatever) I would accede.

I am yet to be convinced that the font has anything to bring to narrative although I have recently finished a novel about an androgynous young person originally named 'Sonny', but I decided (thanks to the word processor) to change it to 'Sønny' - not only to give it a Danish flavour (she/he is a Dane) but also to suggest cross-gender. So there will always be exceptions. But although it works typographically it does not work phonetically for anyone familiar with the ø sound in Danish. Too bad.

I once saw an effective use of bold and regular within the same sentence and among sentences. Aalthough the story was not successful as a whole, the bold signified a change of darkness or mood within the interiority of the monologue or loudness within the character's head. Thus the alternation between regular and bold suggested bi-polar swings within the monologue. Not so successful is the use of it in Haruki Murakami's Kafka on the Shore, where it's used for the interventions of his invisible guardian figure.

I am also very uneasy about whether the use of different colours for words green for the word grass and blue for the word sky and so on - has anything to bring to serious adult fiction (although it may have use for children's books). Coloured words did not arrive with the word processor either. Printing has played with this over the years, but again the word processor allows you to try colour experiments during the creative act of writing to see how it looks. That is new.

However, having looked at more than a thousand short story manuscripts in the last year I can see that quite a few authors have an urge to play graphic artist.

The writer's design palate after stepping off into the act of writing with a word is:

- brackets of various sorts

- margins

- size of type

- sentence/non-sentence

- paragraph/non-paragraph

- prose blocks - episodes, mini-chapters (Sterne did this), subsections, modules sometimes flush left with no indentation of the opening line so that the blocks are perfectly rectangular when justified (which the word processor, by the way, cannot do in any acceptable professional way)

- the nine conventional punctuation marks (not counting three accepted bracket marks)

- italics/roman 
- capitals/lower case

- bold/normal

- indentation left/right

- line of dots

- flush left/right

- bullets

- wriggle

- arrow head horizontal right/left $<>$

- slash left/right

- dashes of different lengths (I cannot discern any graphic logic behind the different lengths of the dash)

- sub-titling - dates and places, mini or mock chaptering

- the mark conventions of narrative breaks (technically known as manuscript 'subordination'-that is, the sub-ordering of the manuscript), isolating text with asterisks or different numbers (usually one to three), sometimes centred, sometimes flush left)

- white spacing between words, sentences, paragraphs, and the prose blocks

- white spacing between lines (many writers have read in how-to-write books that all manuscripts must be submitted double-spaced, so this is not always evidence of author intention)

- the three ways of doing dialogue - quotation marks, the dash, and the use of no punctuation (where the writer relies on the logic of the text flow)

- borders and shadings (probably on the borderline of writer/graphic artist, but sometimes used to, say, insert in the narrative a character's business card

- footnoting as narrative game or joke (again, Sterne did this in the eighteenth century; I did it myself in Loose Living.)

All these devices, if and when used by writers of imaginative prose, involve creative acts: they are not, for example, the prerogative of the editor. Some of these marks are so embedded in the conventions of narrative prose that we no longer see them. Some are used innovatively and cause the reader to almost consciously shift their navigation of the page, although it seems that the sophisticated reader can be agile and sensitive to the formally uncodified marks.

Design decisions made for us by editors and designers that should be revisited, perhaps by writers, include conventional flourishes such as the indenting of the first line, large drop capitals at the beginning of the story, and the near universal use of justification to give the page of text a right-hand flush.

This led me to try to identify what the language or code was that was being expressed in the layouts chosen intuitively or consciously by writers.

These seem to be used by writers intuitively and are perhaps not well established as meaningful conventions (that is hard to know). Some may be used interchangeably in some narrative structures or may be interchangeable in the minds of readers, but it is my observation that writers feel a difference, for example, when using white space to separate sections of the story as distinct from using asterisks (stars), and when they decide to use one asterisk or when they choose to use three. (Sterne played with the asterisk.)

But it seems that sometimes only one of these styles will work or will seem natural to the narrative. 
The biggest movement in layout of the short story has been to move to work with what I call prose blocks or modules. These are sometimes larger units than the paragraph but can be as small as the paragraph. They have no indentation of the first line of the paragraph and are written with a vignettelike or almost aphoristic concision and then closed and separated from the next by three or four white spaces made by the Enter Key or an asterisk break. The writer sometimes achieves an intensity of focus similar say to haiku poetry. Hence this example:

I formulate this maxim: as with the choice of every word, every mark and space on the page is an aesthetic act, intuitive or conscious, and is part of the story-telling.

The short story is a work of art: everything the author does with it is part of the story.

Design is the way of working the narrative on the page, of using and managing the energy of the page.

Every typographic mark has a visual logic?

(For further examples from Best Australian Stories 2004 see the appendix.)

Writers are doing much more than just using these rather commonplace devices, but I quote them as examples of the variations occurring within even these devices.

This essay is far from being an exhaustive or fully thought-through examination of layout in prose fiction, but it is as far as I can take it at this point.

Perhaps innovation in prose fiction has to be questioned as an additional obstacle to reader entry into the story which itself is already asking the reader for special attention. Anything which makes the text look distinctly different and gives off signals which say, 'watch it, this is not journalism, this isn't just information, this is not a report, this is not a profile, this is not a piece of criticism, this is something which may require closer concentration,' is likely to rebuff the tired, lazy, overtaxed, or unadventurous reader.

Even without innovation, the short story and poem in a mainstream general interest magazine setting (say the New Yorker or the Bulletin) does require closer reading than the text surrounding it, such as articles, advertisements, and notes. It asks the reader to shift away from skimming, rapid selectivity both of item and of parts of the item, and highly-practiced techniques of fast reading and information collection.

The poem and story ask for more time and for a shift in intellectual focus, attention, and intellectual openness. They require a degree of strenuous effort 
of a different order to non-fiction prose and journalism. Consequently, it is sometimes left for a slower time of the day, before bed, for example, or kept for some other quarantined time of the day, to be read within a change of pace or surround.

I was interested to read that Tom Keneally, when he was protesting against the detention of refugees by going on a 24 hour hunger strike, used the time to read the short stories in back issues of the New Yorker. What this told me was that he did not read them at the time he was reading the rest of the New Yorker. He'd kept them for reading at 'some other time'.

The innovative typography and layout of verse and short fiction not only signals that the reader is going into deeper water but places a visual layer over the already special request which fiction or verse makes for quality reading time.

The typographer Stephen Banham says that typography and layout are not only a matter of aesthetics. Typography and layout are tied up with ideas - the ideas that are expressed in the text to which typography gives form. I think graphic play is also a narrative tool and at least gives expression to the aesthetic fashion of the culture, sometimes just to distinguish representations of the now from the past. That is, it can be a generational signature or 'look' and that's alright too.

\section{Appendix}

Types of separation marks in prose block modules in fiction-in order to emphasis strength or narrative power, as I tentatively see it - include:

- white space - usually a gap of two or three lines indicated to the editor or typesetter by \# sign and the number of lines - which generally indicates a change of time or place

- single asterisk, which usually signals a change of time or place

- three asterisks, which seems to imply or signal significant or major shifts in time, place or action

- two asterisks separated by a line or long dash, preceded and followed by double-line spacing, which seems to signal a chapter-like change within a short story or a section which is 'meanwhile in another place at the same time.' It can also separate and disconnect a section, for example, a personal introduction or note that is not part of the narrative or pretends not to be part of the narrative. For example, 'What follows are pages of a nineteenth century diary found in an attic'.

- heads (a subtitle for a section of the story), time and date lines, numbers, epigraphs, locations, and characters' names, which all spell out to the reader the nature of the change in the narrative movement

- the character (§), known as a section sign in the US and as a paragraph sign in Europe, which generally separates paragraphs in law contracts. (For that reason, $\S$ is sometimes used to symbolise law in general.) The varying names reflect the variation in usage. Australians do not seem to use it. I am not sure what weight it carries as a section break. It would perhaps indicate a very significant if not total narrative shift.

- the tilde $(\sim)$. I am not sure whether this has any narrative meaning. 
Apart from being a short story writer himself, Frank Moorhouse is editor of Best Australian Stories for Black Inc. Recently, he was a judge of the Josephine Ulrick National Short Story Competition run by Griffith University and the Glen Eira National Short Story Competition. Two years ago he was visiting writer at the University of Texas in Austin where he gave a graduate student semester workshop on short narrative.

TEXT Special Issue

No 4 October 2005

http://www.griffith.edu.au/school/art/text/

Editors: Wenche Ommundsen and Maria Takolander

General Editors: Nigel Krauth \& Jen Webb

Text@griffith.edu.au 